\title{
Eletrônica Criativa: Uma estratégia metodológica para o Ensino e Aprendizagem de conceitos de eletricidade e/ou eletrônica na modalidade Híbrida de Ensino: Introdução
}

Creative Electronics: A methodological strategy for Teaching and Learning concepts of electricity and/or electronics in the Hybrid Teaching Mode: Introduction

\author{
Marisa Almeida Cavalcante ${ }^{* 1}$, Elio Molisani Ferreira Santos ${ }^{1,2}[$ \\ ${ }^{1}$ Universidade Federal do Amazonas, Departamento de Física, Manaus, AM, Brasil. \\ ${ }^{2}$ Universidade de São Paulo, Escola Politécnica, Programa de Pós-Graduação em Engenharia Elétrica, SP, Brasil.
}

Recebido em 20 de maio de 2021. Revisado em 08 de julho de 2021. Aceito em 09 de julho de 2021.

\begin{abstract}
Este trabalho apresenta uma proposta metodológica e recursos didáticos para o ensino híbrido de conteúdos e conceitos na área de eletricidade e eletrônica, integrando arte, ciência e cultura, que foi aplicada em dois cursos de formação continuada para professores do ensino básico da Secretaria Municipal de Educação de São Paulo (SME-SP). Tendo por base estratégias de aprendizagem ativa, foram utilizadas dinâmicas envolvendo o desenvolvimento de narrativas aliadas à construção de painéis interativos $2 \mathrm{D}$, trazendo à tona a concepção de arte interativa, onde diferentes representações do objeto surgem a partir da interação humana com a obra observada. A interação destes painéis é decorrente da prototipação de sistemas eletrônicos que integram sensores, atuadores e outros dispositivos controlados com Arduino, virtualmente simulados através do aplicativo Tinkercad em aulas remotas. Com isso, agregamos significado e propósito para a aprendizagem de eletrônica, tornando uma tarefa motivadora e instigante para o estudante. As estratégias de aprendizagem em eletricidade básica para, dentre outros objetivos, alicerçar a construção de conhecimentos em computação física, caracteriza o que chamamos de Eletrônica Criativa. A natureza lúdica e híbrida desta proposta permitiu aos professores participantes desenvolver projetos e atividades que puderam ser aplicadas em suas aulas remotas, com maior interação e motivação dos estudantes. Para os anos de 2021 e 2022 devemos oferecer um curso de Computação Física Avançado com carga horária mínima de 20 horas, voltados a professores multiplicadores, para tratar com maior grau de profundidade conteúdos de eletrônica, tais como, funcionamento de transistores e sua utilização para o funcionamento adequado de motores, limites de operação do simulador Tinkercad para o estudo de propriedades de diodos, uso de circuitos integrados como portas lógicas, dentre outros temas trazidos pelos professores cursistas, mediante a necessidade de seus projetos e planos de aula. Pretendemos apresentar estas propostas mais avançadas oportunamente em uma segunda versão deste artigo.
\end{abstract}

Palavras-chaves: Eletrônica criativa, Aulas remotas com o Tinkercad, Ensino híbrido, arte-ciência e cultura na aprendizagem de eletrônica, Computação Física.

This paper presents a methodological proposal for teaching and learning content and concepts in electricity
and/or electronics integrating art, science, and culture, in a dynamic that involves the construction of $2 \mathrm{D}$
interactive panels anchored in the concept of interactive art in which different representations of the object
occur from human interaction with the observed. Narratives are integrated into the electronic panels with the
assembly and schemes prototyped in online simulators like Tinkercad, with or without programming with the
Arduino. The dashboard is built to create an interface between the learner's imagination and the simulator's
virtuality in basic electronics. Thus, we discard the purpose of learning for electronics, but learning electronics to
make something that is motivating and instigating. This motivation moves the student to learning to learn and
learning to do by becoming involved in electronics that makes the most sense in their lives. The learning strategies
in basic electricity to build the knowledge for physical computing characterizes what we call Creative Electronics.
The playful and hybrid nature of this proposed work allowed teachers to develop projects and activities that
were applied in their remote classes and, according to testimonials, gained greater motivation from students. For
the years 2021 and 2022 we intend to offer an Advanced Physical Computing course with a 20-hour minimum
duration, focused on multiplication teachers, to give a more detailed treatment of electronics content, such as
the operation of transistors and their use for the proper functioning of motors, the limits of operation of the
Tinkercad simulator to study the properties of diodes, the use of integrated circuits as logic gates, among other
topics brought by the teacher trainees, according to the needs of their projects and lesson plans. We expect to
present these more advanced proposals in the next version of this work. Keywords: Hybrid environments, art-science and culture in basic electronics learning, e-learning using Tinkercad, physical computing online.

\footnotetext{
* Endereço de correspondência: marisac@ufam.edu.br
} 


\section{Introdução}

Durante o ano de 2020, o mundo inteiro sofreu um grande impacto em todos os seus setores em razão do isolamento social ocasionado pelo surto pandêmico do SARS-COV 2, popularmente conhecido como Covid-19, que surgiu na China ao final do ano 2019. Os efeitos afetaram não apenas a saúde e a vida dos milhões de contaminados em todo o planeta, mas também, alterou de modo significativo a vida profissional de muitos trabalhadores e comerciantes. Todos tivemos que buscar apoio em recursos tecnológicos digitais para garantir parte de nosso sustento. A prestação de serviços foi um dos setores que mais se reinventou, possibilitando a todos, confinados em suas residências, acesso a produtos por sistemas de delivery.

No setor educacional não poderia ser diferente. De acordo com a Unesco [1, cerca 850 milhões de estudantes e 49 países foram e estão sendo afetados pelo fechamento das escolas.

É indiscutível que este acontecimento ampliou de modo inimaginável as desigualdades e trouxe um prejuízo incomensurável a crianças e jovens em condições de vulnerabilidade. Tanto do ponto de vista educacional, quanto financeiro, abriu-se um abismo desproporcional entre as classes sociais, uma vez que uma grande parcela da população menos favorecida perdeu o emprego e o sustento de sua família.

Para estas crianças e jovens, o acesso à educação ficou estagnado, a alimentação que muitos recebiam em suas escolas também foi suspensa e conduziu muitas famílias brasileiras para a linha de pobreza extrema.

E continuamos ainda aos tropeços com algumas iniciativas para retorno as aulas presenciais em escolas públicas, principalmente para atender a população que não possui qualquer tipo de infraestrutura de acesso à internet para participar de aulas remotas síncronas ou assíncronas.

No ensino superior, muitos esforços foram empenhados para que não houvesse o cancelamento das atividades. Em muitas universidades públicas e particulares, professores e alunos continuaram com as atividades de forma remota pela internet, por meio de ambientes virtuais de aprendizagem.

Os educadores que no dia 10 de março de 2020 dormiram professores presenciais, acordaram dia 11 de março como professores remotos. Foi um salto, quase que quântico, para adiantar pelo menos duas décadas de tecnologia e estratégias educacionais em cerca de um a dois meses de aulas.

Importante que se diga que esta não foi apenas uma corrida das Instituições de Ensino Superior, mas também da maioria das escolas de nível básico, públicas e privadas para impedir uma paralização total da educação.

O Ensino Remoto é uma modalidade diferenciada de ensino, com momentos síncronos em ambiente virtual onde professores e estudantes se encontram para o desenvolvimento de atividades, esclarecimento de dúvidas, aprofundamento de temas etc. Nesta modalidade de ensino os momentos assíncronos também devem ser privilegiados e bem planejados pelos professores, com a finalidade de potencializar os encontros síncronos e obter maior eficiência no aprendizado dos estudantes.

Segundo [2], uma decisão de implantação imediata de Ensino Remoto Emergencial (ERE) está baseada em algumas premissas. São elas:

- professores e estudantes com fácil acesso à internet e totalmente equipados para isso;

- estudantes e professores de saúde ideais, tanto física quanto psicológicas, para dar início as atividades letivas;

- ensinar é transmitir conhecimento e, por esta visão, o professor pode fazê-lo de modo síncrono ou assíncrono, tal como o faria presencialmente no velho modo tradicional; meramente expositivo com horas de projeção de Slides e conteúdo disponível online. E acompanha o pacote fichas de exercícios e textos teóricos de complementação.

Não é difícil perceber que com estas premissas e visão totalmente distorcidas de ensino, teríamos altos índices de evasão e uma crise educacional sem precedentes na história deste país.

"... desenvolver um Ensino Remoto Emergencial não implica transpor meramente $o$ ensino presencial para o contexto remoto. Ainda que o ensino, no contexto da pandemia, tenha caráter emergencial, não pode acontecer de modo improvisado." ...... Levar a sério o Ensino Superior requer cuidado com aquilo que faremos neste período emergencial e após a emergência; requer, também, decisões de acordo com as concepções que definem esse nível de ensino. Apesar de se tratar de uma situação emergencial, o ensino não pode constituir prática sem planejamento, de improviso e com características meramente burocráticas. É importante que a adoção do ensino remoto envolva oportunidades para planejar condições de ensino que promovam o desenvolvimento de aprendizagens de Ensino Superior, mais do que de adesão e repetição de conteúdo." [2] pp. 9 e 10

Com este olhar e com esta preocupação, os autores deste trabalho, procuraram buscar estratégias que propiciassem aos professores participantes dos cursos de formação continuada oferecidos proporcionar maior interatividade com e entre os estudantes em ambientes virtuais, bem como o uso de ferramentas digitais para acompanhar o aprendizado de seus estudantes e sobretudo recursos e metodologias que fossem mais 
motivadoras. Dentro desta perspectiva procuramos neste trabalho:

- apresentar atividades experimentais online para o caso de disciplinas na área de ciências da natureza e exatas, tendo em vista a grande importância desta vivência na aprendizagem destes conteúdos e de suas aplicações;

- trazer diferentes opções para que atividades e projetos em equipe sejam desenvolvidas remotamente, já que o modelo de aprendizagem colaborativa tem mostrado bastante eficiência tanto no aumento do nível acadêmico dos estudantes quanto no desenvolvimento de habilidades socioemocionais [3];

- apontar caminhos para planejamento de atividades assíncronas, tendo em vista a sua extrema relevância para garantia na qualidade de ensino e redução no índice de evasão para esta modalidade de ensino.

Neste trabalho são apresentadas as etapas envolvidas na estruturação das estratégias adotadas na proposta aplicada, contextualizando-as de acordo com trabalhos e artigos existentes na literatura que amparam toda a trajetória pedagógica traçada pelos autores.

\section{Eletrônica criativa uma proposta para o ensino de eletrônica e/ou eletricidade básica para iniciantes}

\subsection{Contextualização: Porque o tema Eletrônica e/ou eletricidade}

Este trabalho traz uma proposta aplicada em dois cursos de formação continuada de professores da Secretaria Municipal de Educação do Município de São Paulo que ocorreu remotamente em 2020 e que deu origem a publicação de um livro digital interativo em licença Creative Commons [4] que reúne atividades, em diferentes áreas de conhecimento, permeadas por diferentes tecnologias e que podem ser aplicadas em sala de aula, seja no formato físico ou virtual, com propostas que ampliam as possibilidades de integrações curriculares.

Para o curso de educação continuada em Computação Fisica, foco deste artigo, tínhamos como tarefa primordial mostrar aos profissionais em exercício a importância da compreensão de conceitos básicos em eletrônica para o desenvolvimento de projetos na área de tecnologia com transversalidade, como está posto nas diretrizes curriculares da BNCC, $[5]$.

Considerando os impactos das transformações da sociedade mediante os grandes avanços tecnológicos, a BNCC, na educação básica, sugere a criação de uma área destinada as Tecnologias Digitais e a computação. Diferentes dimensões que caracterizam a computação e as tecnologias são consideradas como fundamentais na formação dos jovens tais como: desenvolvimento do pensamento computacional a compreensão do mundo digital, o processamento e a transmissão e distribuição de informações por meio de tanto de artefatos físicos como digitais. Com isso, nossas crianças e jovens precisam, na sua formação, de uma compreensão mínima no processamento de informações físicas provenientes, como por exemplo, uso sensores e a ação de atuadores, como ocorre nos microcontroladores como o Arduino e Micro:Bit, já que todo este processo faz parte da alfabetização tecnológica dos indivíduos.

Para atender esta necessidade a eletrônica entra como uma das protagonistas deste processo, tendo em vista que é preciso o mínimo de conhecimento e princípios básicos, que envolve desde a captura de um sinal, seu processamento e programação.

Mas não é tarefa fácil incentivar a compreensão deste universo de automações para jovens ou profissionais que não apresentam afinidade para esta área do conhecimento, visto que em geral é considerada como uma área de difícil compreensão e com uma boa dose de pré-conceito, já que muitos acreditam que eletrônica é destinada aos "nerds" das áreas de exatas.

A maior parte dos professores participantes do curso de formação continuada não possuem formação na área de exatas e/ou engenharias, mas eram professores responsáveis pelos laboratórios destinados a área de tecnologia. A tarefa destes professores é desenvolver projetos de programação, incluindo o uso de microcontroladores como o Arduino. Por falta de conhecimento específico muitos deles se restringiam a copiar projetos físicos disponíveis na internet, sem qualquer conexão lógica e estruturada entre o mundo físico e as variáveis introduzidas nas linhas de programação. Disso, decorre uma limitação no desenvolvimento da criatividade dos estudantes já que a ausência de informações acaba por impor mera reprodução do que encontravam em suas buscas na web.

Além de conhecimento mínimo na área, a montagem e estruturação de projetos em eletricidade básica e/ou eletrônica necessita do desenvolvimento de uma visão sistêmica em detrimento de um raciocínio sequencial ou localizado, o que em geral não ocorre, mesmo para estudantes de graduação com afinidades para esta área do conhecimento, segundo 6].

Para propiciar o desenvolvimento de uma visão mais ampla de sistemas, devemos conceber projetos que tragam visualizações imediatas de suas hipóteses e mantêlos motivados. Para isso uma das alternativas que tem se mostrado bastante eficaz é trazer o aprendiz para ambientes de experimentação, mas numa concepção advinda da cultura Maker, do aprender fazendo. Neste espaço os estudantes são acompanhados e orientados pelos professores no desenvolvimento de projetos ou na resolução de problemas. Nesta construção as concepções alternativas vão dando lugar ao conhecimento científico por meio de testes e num processo constante de investigação.

No caso específico da eletrônica, a junção entre painéis eletrônicos e arte interativa nos oportunizou trazer 
todas estas concepções de modo motivador, instigante e criativo. Criando um ambiente propício para o desenvolvimento do espírito investigativo. Esta integração entre arte e ciência será mais bem apresentada no item 2.2.

\subsection{Painéis $2 \mathrm{D}$ e contribuições para uma visão sistêmica no desenvolvimento e análise de circuitos elétricos e/ou eletrônicos}

Uma das premissas para a motivação, está na resolução de problemas que integrem a realidade dos estudantes, de acordo com seus desejos e aspirações. Diante desta perspectiva a compreensão de conceitos de eletrônica, bem como a manipulação dos componentes eletrônicos e suas conexões, emergem da necessidade de resolver algum desafio que lhes sejam significativos. Como uma das trajetórias possíveis buscamos integrar arte e ciência na construção de painéis interativos vinculados narrativas. Neste caminho os aprendizes fortalecem suas relações sociais por meio de uma aprendizagem colaborativa.

A construção de painéis interativos foi inspirado nos trabalhos desenvolvidos por Jie Qi [7. Dentre os projetos e trabalhos desenvolvidos pela autora, temos o Pu Gong Ying Tu, que se traduz do chinês como pintura dente-deleão, que é uma exploração da mistura de elementos da pintura a tinta tradicional cor, textura, composição com os das tecnologias contemporâneas; eletrônica, detecção, atuação, computação e dinamismo para explorar novos modos de contar histórias e interagir com o mundo digital.

A Figura 1 mostra uma das paisagens com um circuito projetado que proporciona, a partir de sopros em microfones, diferentes representações com alterações de cores para os LEDs, bem como a localização do LED a ser aceso.

Esta pintura é feita em duas partes (Figura 2): na parte superior está uma pintura tradicional a pincel com tinta chinesa e na parte inferior um circuito feito com fita de cobre, LEDs, sensores e microcontroladores programados. Entre eles está um tecido branco para difundir o colorido dos LEDs, adicionando textura à luz.

"Assim como as linhas de tinta constituem a forma da paisagem, o mesmo ocorre com as linhas de traços de fita de cobre cuidadosamente colocados para criar sua própria cena (Figura 3). Enquanto essas linhas de cobre atuam como conexões elétricas para sinais no circuito, sua forma também segue os contornos das flores, o fluxo das sementes e a composição da paisagem criando outra

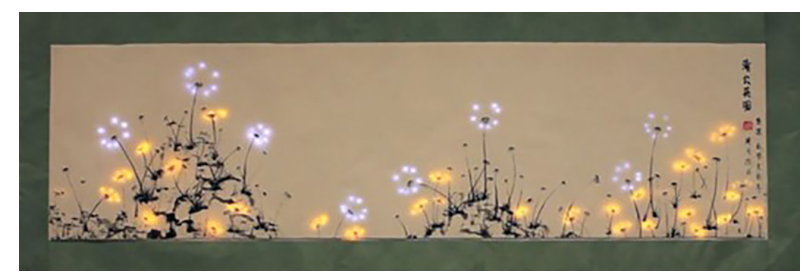

Figura 1: Paisagem interativa usando pintura a tinta chinesa.

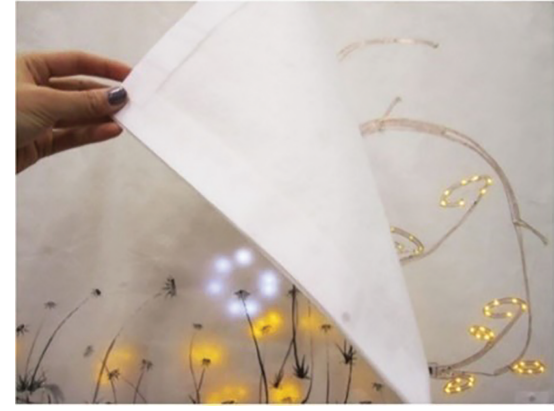

Figura 2: $\mathrm{Na}$ parte superior temos a pintura em tinta chinesa e na inferior um circuito feito com fitas de cobre e com LEDS sensores e microcontroladores programados.
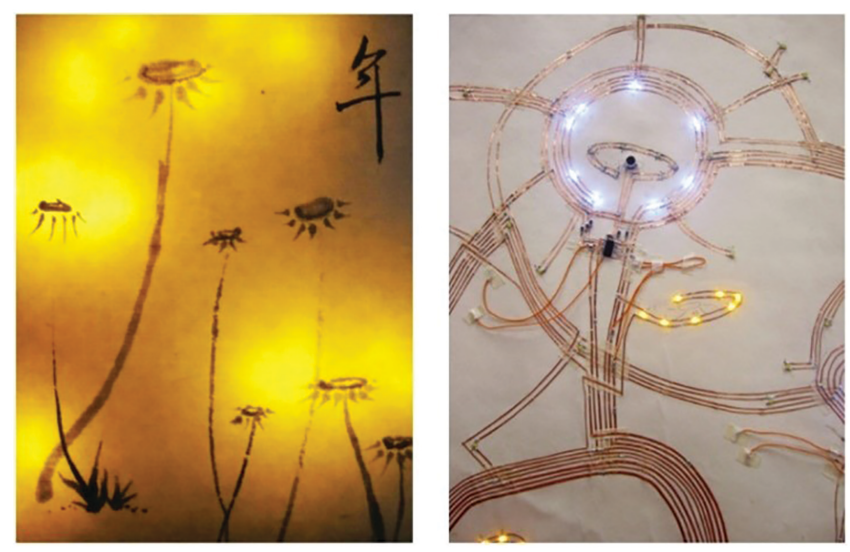

Figura 3: Composição dos traços do circuito seguindo os contornos das flores na paisagem.

camada de representação, tanto computacional quanto visual" 8.

Assim como a autora utiliza conceitos de "Obras Híbridas: Físico e Digital na Integração de Competências de Design e Construção" 9], passamos a utilizar esta concepção de produtos híbridos para uso educacional. Ou seja, a eletrônica é estudada como um meio para a criação de painéis que integram narrativas educativas a circuitos elétricos ou eletrônicos com algum nível de interatividade.

A sobreposição dos desenhos ou figuras a circuitos elétricos e/ou eletrônicos possibilitam aprender eletrônica não pela eletrônica, mas para produzir algo que tenha algum significado para o aprendente e por esta razão a motivação é algo inerente ao processo de aprendizado.

\section{Eletrônica e eletricidade na construção de produtos/obras híbridos(as) em ambientes remotos}

A Eletrônica Criativa visa dentre outras coisas, desenvolver a criatividade e inventividade dos estudantes por meio da construção de painéis que atendam a uma demanda temática e seja representada por uma imagem 
ou um desenho que contenha interatividade e conduza à diferentes designs de produtos.

Trata-se de um projeto físico que se deseja produzir e, por esta razão, traz consigo a concepção da cultura $M a$ ker integrando o aprendizado ao ato de fazer e construir algo. Por conta disso, possibilita o desenvolvimento de diferentes habilidades incluindo as socioemocionais.

No entanto, em razão do isolamento social imposto pela pandemia Covid-19, um projeto desta natureza parece em uma primeira análise inviável, já que pressupõe o uso de um espaço físico de construção.

Para o planejamento de atividades desta natureza, devemos prever o desenvolvimento de protótipos para testes. Para isso, cálculos devem ser realizados de modo a evitar sobrecargas em componentes garantindo o funcionamento adequado de todo o sistema. Os simuladores surgem como um facilitador no desenvolvimento destes protótipos; o que não deve ser compreendido como uma forma de se abolir os cálculos matemáticos e modelos físicos necessários na resolução destes sistemas. Lembrando que no desenvolvimento destes simuladores, os algoritmos estão fundamentados nos modelos físicos conhecidos e que devem ser objetos de investigação e estudo do público-alvo do trabalho em tela.

Por meio destes simuladores podemos observar na prática o efeito das equações matemáticas aplicadas na resolução de circuitos elétricos e suas previsões, promovendo testes de sobrecarga em tempo real, permitindo ao aprendiz maior compreensão do fenômeno e sua modelagem, facilitando a inserção dos modelos físicos para aqueles que estão iniciando seus estudos nesta área de conhecimento.

É importante chamar a atenção que o uso de simuladores sempre estiveram presentes de forma complementar, como apoio as atividades experimentais presenciais. De acordo [10], os resultados no uso destes simuladores para a aprendizagem em eletricidade demonstram que podem ser ferramentas educacionais até mesmo mais eficazes do que equipamentos de laboratório reais, tanto na compreensão dos conceitos quanto na facilidade no manuseio de medidores elétricos virtuais. A constatação dos autores decorre do fato de que, nestes simuladores, os instrumentos virtuais exercem a mesma função dos utilizados em circuitos reais e são igualmente conectados, oferecendo uma vivência prática e experimental ao estudante.

Atualmente, contamos com uma grande variedade de simuladores que permitem estas modelagens com interfaces amigáveis e bem intuitivas. Além de possibilitar testes, também contribuem para o desenvolvimento de estruturas cognitivas necessárias para a construção de conhecimento em eletrônica. A Tabela 1 mostra alguns destes simuladores disponíveis online.

O ensino e aprendizagem baseado em eletrônica criativa, além do potencial motivador que lhe é característico, também constitui uma ferramenta digital importante para a modalidade híbrida de ensino, tendo em vista que os protótipos podem ser desenvolvidos remotamente em momentos síncronos ou assíncronos.

O curso de educação continuada apresentado neste artigo foi estruturado para propiciar aos professores coordenadores dos Laboratórios de Educação Digital - LED da SME-SP - hoje concebidos como Espaços Maker, algum conhecimento em eletricidade básica para permitir maior segurança aos professores na orientação e desenvolvimento de projetos em automação com seus estudantes utilizando placas de microcontroladores como o Arduino. Isto porque a maioria deles, em razão de suas áreas de formação, desconhecem conceitos como corrente elétrica, diferença de potencial, resistência elétrica, praticamente inviabilizando orientar, inovar e instigar a criatividade de seus estudantes em qualquer protótipo em computação física.

Assim, foi necessário em primeiro lugar romper com uma ideia preconcebida de que desenvolver esquemas elétricos e conduzi-los a uma montagem real é algo apenas para técnicos ou pessoas com muita habilidade nesta área. De outro modo foi importante que as atividades correlacionadas a montagens de sistemas elétricos fossem conectadas a algo que fizesse sentido ao professor e a sua área de atuação. Isto foi possível por meio da criação de narrativas para a construção de painéis eletrônicos interativos. A motivação é elemento fundamental para impulsionar o indivíduo a aprender algo que ele considera muito distante do seu domínio.

Neste curso de formação continuada os simuladores possibilitaram desenvolver os seguintes conteúdos e conceitos:

- Conceito de corrente elétrica, diferença de potencial e resistência elétrica e o uso adequado de multímetros, para a medida destas grandezas elétricas.

- Conceito de resistência equivalente com a associação de resistores e compreender de que maneira estas associações interferem na corrente elétrica em um circuito

- Compreender o princípio básico de funcionamento de semicondutores como sensores e atuadores, tais como o atuador LED (light-emitting diode) e o foto resistor LDR (Light Dependent Resistor), ambos utilizados com frequência em projetos em robótica.

- Compreender o processo de medida física de grandezas, tais como luminosidade, pressão, temperatura, etc. por meio de sensores, muitos deles disponíveis no Tinkercad e a relação entre estes sinais e os valores decimais indicados no monitor serial do microcontrolador Arduino.

Há, no entanto, de se considerar que todos estes conceitos e conteúdos foram construídos a partir de desenvolvimento de circuitos e seu planejamento, de modo colaborativo, para atender a solução dos painéis eletrônicos interativos. Nestas construções foi possível ao professor cursista perceber, por exemplo, 
Tabela 1: Relação de alguns simuladores em eletrônica disponíveis online.

\begin{tabular}{|c|c|c|c|}
\hline$\overline{\text { Simulador }}$ & Resumo & Exemplo de circuito & referência \\
\hline$\overline{\text { DCACLAB }}$ & $\begin{array}{l}\text { É um simulador com uma aparência bem } \\
\text { próxima aos circuitos reais. As conexões } \\
\text { são realizadas pelo usuário em placa de } \\
\text { apoio. } \\
\text { Uso gratuito limitado. }\end{array}$ & $\begin{array}{l}\text { https://dcaclab.com/es/experiments } \\
\text { /31261-proyecto-tsf-y-c-dot-i-t } \\
\text { (excelente para circuitos analógicos } \\
\text { muito didático) }\end{array}$ & 11 \\
\hline
\end{tabular}

Tinkercad (simulador de circuitos)

PhET (simulador laboratório AC-DC em HTML 5)
É uma plataforma livre em que você tem uma galeria com vários exemplos de simuladores. Atualmente podemos simular circuitos com microcontroladores como o Arduino, Micro:bit e ATTINY85 (microcontrolador de mais baixo custo disponível)

A plataforma PhET traz uma série de simulações em diferentes áreas do conhecimento e tem sido largamente utilizada pelos professores em variados níveis de ensino. Apresenta um banco de atividade em muitos idiomas e que podem ser acessadas e utilizadas livremente, reservados o direito de autoria (licença Creative Commons)

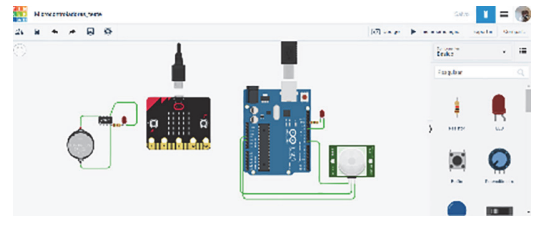

https://www.tinkercad.com/things /e1OmKfNOCyX (exemplo de simulador com o uso dos microcontroladores disponíveis no simulador)

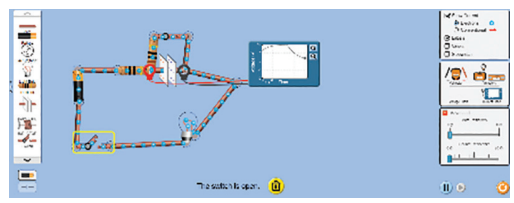

https://phet.colorado.edu/sims/htm l/circuit-construction-kit-ac/latest/c ircuit-construction-kit-ac_en.html

Exemplo de carga e descarga de capacitor e a visualização da ddp nos terminais do capacitor. Os resistores associados ao capacitor apresentam o mesmo valor tanto para a carga quanto para a descarga do capacitor. Neste exemplo $\mathrm{C}=0,1$ $\mathrm{F}$ e resistor $\mathrm{R}=10 \Omega$. Este simulador Lab AC-DC em HTML 5 encontra-se em teste. o funcionamento de um LED e sensores de luz como o LDR como materiais semicondutores e com comportamentos diferenciados. Perceberam que estes componentes, apresentam características diferenciadas tais como, condutividade dependentes da corrente elétrica (sentido e valor) no caso dos LEDs ou da intensidade de luz incidente sobre eles no caso dos LDRs. Os professores cursistas associaram medidores em diversos componentes dos circuitos construídos e puderam notar qualitativamente as características destes semicondutores. Todas estas descobertas aconteciam à medida que os protótipos eram desenvolvidos.

Neste artigo são apresentados os protótipos desenvolvidos e suas conexões com narrativas elaboradas, adequadas a faixa etária das crianças, trazendo a possibilidade de um aprendizado mão na massa aliando tecnologia e metodologias de investigação cientifica.

Neste trabalho apresentamos o curso introdutório e as estratégias adotadas para que professores que não apresentavam qualquer conhecimento em computação 
física, pudessem adequar suas aulas as faixas etárias das crianças, permitindo que este mundo físico associado a tecnologias digitais possa ser compreendido de modo lúdico incentivando a inventividade e criatividade dos estudantes.

No entanto, é importante ter em mente que os conhecimentos em eletrônica devem avançar ainda mais, para que os professores ganhem maior plenitude em seus conhecimentos e desenvolver projetos mais complexos com seus estudantes. Para isso planejamos oferecimento de cursos mais avançados de formação continuada em Computação Física para os anos de 2021 e 2022.

Para este avanço de conteúdo pretendemos tratar os seguintes temas:

- Funcionamento de transistores e maior compreensão das propriedades dos diodos,

- Desenvolvimento protótipos com fontes de tensão variáveis e uso e manuseio de osciloscópios para visualização e medidas destes sinais

- Compreensão do funcionamento das portas de saídas digitais PWM (Pulse Width Modulation) como portas que simulam saídas analógicas com consequente visualização destes sinais por meio de osciloscópio

- Uso de circuitos integrados como as portas lógicas para maior domínio da eletrônica digital correspondentes resoluções nas representações do mundo analógico.

- Compreensão de conceitos básicos de eletromagnetismo para o uso adequado de relés com bloqueio de sinal de retorno, e a compreensão de outros componentes eletrônicos importantes e repletos de conteúdos de física.

Para o desenvolvimento destes temas os tomaremos como base atividades e recursos didáticos desenvolvidos pelos autores direcionados para estudantes do curso de licenciatura em Física Universidade Federal do Amazonas (desde 2017) 14 e para estudantes em curso de Ciência da Computação da Pontifícia Universidade Católica de São Paulo (desde 2010) [15]. Estes recursos envolvem desde estudo de circuitos de corrente alternada, carga e descarga de capacitores, análise de circuitos elétricos em comparação, até resultados obtidos em experimentos em laboratórios remotos como o Rexlab [16], construção de curva características de LEDs no simulador Tinkercad e o confronto com dados reais por meios de experimentação remota do Laboratório Remoto Universidade de Praga - República Tcheca [17, etc. Estas atividades que exploram com maior aprofundamento os conteúdos, tanto em eletrônica quanto em eletricidade, e são úteis para a formação inicial de professores de Física e profissionais na área de Ciência da computação, serão apresentadas em uma sequência deste artigo (Parte 2 de 2), com as respectivas adaptações. Apenas para exemplificar uma das aplicações que permite maior reflexão sobre os limites impostos pelo simulador Tinkercad, [18] apresenta uma proposta experimental que será tratada oportunamente.

\section{Formação inicial e continuada de professores em eletrônica criativa}

Considerando, portanto, o curso introdutório de formação continuada para professores da Secretaria $\mathrm{Mu}-$ nicipal de Educação de São Paulo, tivemos carga horária de 20 horas. Sendo 12 horas de encontros síncronos, 4 horas de atendimento personalizado online e 4 horas de atividades assíncronas. O planejamento das atividades foi alicerçado no modelo TPACK (Technological Pedagogical Content Knowledge) [19]. A Figura 4 mostra um esquema do modelo PTACK.

Para possibilitar a articulação entre os três saberes no modelo PTACK e uma participação equilibrada de todos os envolvidos no processo de ensino e aprendizagem, foram desenvolvidas atividades em Eletrônica Criativa que caracteriza uma superposição entre o imaginário do cursista e a virtualidade do simulador numa área considerada abstrata que é a eletrônica básica, caracterizando a criação de "Obras Híbridas" em arte interativa [7].

a. Agentes motivadores no planejamento de estratégias: Interface entre Arte-Ciência-Cultura no aprendizado.

As propostas e estratégias por meio da Eletrônica Criativa tem como princípio básico uma aprendizagem compartilhada, baseada na resolução de problemas que sejam motivadores. Para isso devemos garantir um planejamento bem estruturado de atividades em que o professor assume o papel na mentoria e/ou orientação, e

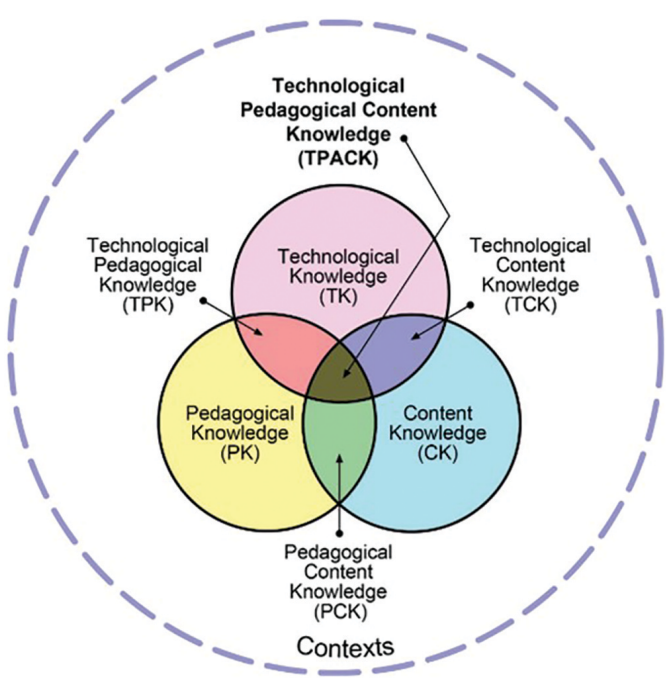

Figura 4: Framework TPACK e a integração dos seus componentes. Este modelo institui e busca explicar a base de conhecimento docente para a integração das tecnologias em contextos educacionais, a partir do alinhamento com abordagens pedagógicas e ensino de conteúdo específicos Fonte http:// tpack.org 


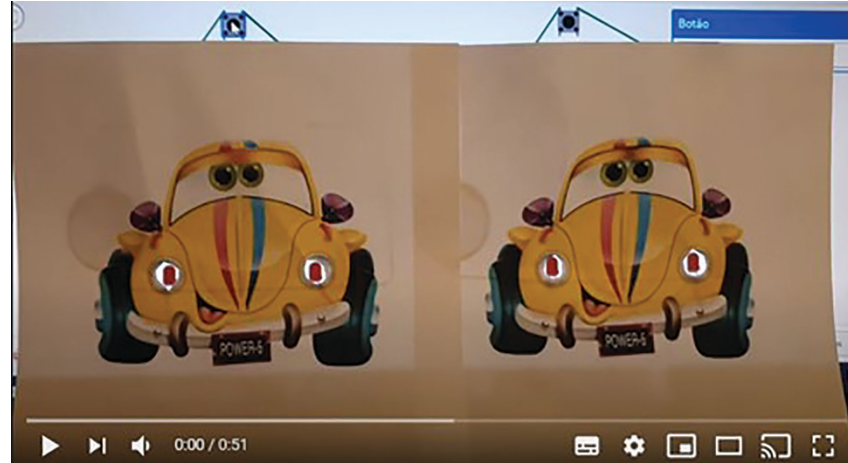

Figura 5: Imagem retirada do vídeo tutorial (parte 2 de 4) disponibilizados no YouTube [20].

que possa acompanhar o processo de aprendizagem tanto individualizado quanto na atuação da equipe durante a resolução dos desafios.

Para isso produzimos cartões de atividades com diferentes etapas de interação desde a reflexão e o contato individualizado do professor cursista com o material até o desenvolvimento de um projeto, ou resolução de um problema em equipe para a aplicação e compartilhamento de conhecimentos.

Tomando como princípio a construção de painéis $2 \mathrm{D}$ interativos, consideramos um desafio em que, para solucioná-lo, será necessário compreender alguns conceitos:

- Identificar corrente elétrica e a sua interferência no aumento de brilho de um LED;

- Compreender como podemos alterar a corrente elétrica em um circuito elétrico;

- Entender como a associações de resistores em série e paralelo podem interferir na corrente elétrica de um circuito;

- Compreender o significado de resistência equivalente em um circuito.

Para dar maior dinamicidade às atividades nos ambientes virtuais, o cartão de atividades contou com vídeo descritivo, como indicado na Figura 5. Neste exemplo, temos dois circuitos que produzem efeitos distintos no desenho apresentado. Ao clicarmos na chave pushbotton, o fusca localizado a direita da imagem acende seus faróis com maior intensidade (farol alto) enquanto na imagem localizada a esquerda os LEDs acendem com menor intensidade (farol baixo). Neste painel temos as imagens de um fusca que foram impressas e superpostas na tela do computador sobre dois circuitos construídos no simulador Tinkercad. Esta superposição dá origem a uma espécie de interface que correlaciona a pintura ou desenho do mundo real, ao circuito virtualmente planejado e simulado.

Convém notar que este painel pode ser construído no mundo físico, com o uso de LEDs, baterias usando, por exemplo, tiras de papel alumínio para as conexões entre os componentes.
De acordo com [20], no vídeo 1 de 4, temos a apresentação de um produto híbrido resultante da integração de uma imagem à um simulador de circuitos elétricos/ eletrônicos. A questão norteadora para a resolução deste desafio consiste em justificar a diferença nestas representações. Nesta $1^{a}$ etapa, uma livre discussão se estabelece em um encontro síncrono em que os estudantes apresentam suas hipóteses para justificar a diferenças observadas entre as duas imagens. Isso permite ao professor fazer um levantamento das as concepções alternativas.

Para agrupar as informações e as hipóteses de cada participante, podemos utilizar quadros online tais como; Padlet 21], Miro [22, Jamboard [23], dentre outros. O importante sobre o uso destas ferramentas, é favorecer a interação professor-aluno/aluno-aluno num ambiente virtual e o consequente registro para posterior análise das concepções alternativas. Estas concepções registradas nestes quadros online, são extremamente úteis e servem como pano de fundo para a idealização dos procedimentos e estratégias de ensino.

É muito importante que os estudantes possam testar suas hipóteses e propor circuitos que atendam as representações estabelecidas. Para isso, é fundamental o planejamento e a criação de cartões de atividades que auxiliem os estudantes na organização e no teste de suas hipóteses, para posterior postagem em ambiente digital. Este trabalho pode ser individual ou coletivo, a depender da estratégia do professor.

Para iniciantes em eletricidade e/ou eletrônica recomendamos o uso do simulador KIT DC do PhET (Tabela 2). O seu uso permite migrar com mais segurança para o simulador Tinkercad, que traz um design para os componentes muito semelhante a realidade física.

Na literatura encontramos vários trabalhos que apresentam o simulador PhET como um recurso muito eficiente para o desenvolvimento de conceitos em eletricidade. Selecionamos alguns como; [10, 24,26] e 27. Para todos eles, temos um "fio condutor" comum, que consiste em desenvolver nos estudantes uma visão mais ampla e menos pontual de circuitos elétricos. Além disso as atividades são planejadas para que os estudantes possam transformar suas concepções alternativas em conhecimento científico e significativo. A maioria destes artigos, estabelece vínculos dos circuitos propostos com situações do cotidiano como, por exemplo, a distinção do tipo de associação que se utiliza nas instalações elétricas residenciais ou comerciais.

Todos os artigos, descrevem a grande motivação dos estudantes ao interagirem com o simulador na busca de soluções de problemas e apontam que as discussões em equipe ocorrem de modo espontâneo numa dinâmica colaborativa.

É unanime nesses trabalhos que um dos obstáculos de aprendizagem em eletricidade está na dificuldade de abstração dos estudantes em generalizar os conceitos. No nosso olhar, a partir das leituras destes trabalhos, notamos que apesar de se trazer problemas correlacio- 
Tabela 2: Painéis e narrativas desenvolvidas pelos professores da Secretaria Municipal de Educação de São Paulo.

Autoria: Douglas Maris Antunes Coelho; EMEF Prof. Wanny Salgado Rocha; DRE Penha: Página 18 do catálogo [33] https://doi.org/10.5281/ZENODO.4618289

Superposição do desenho com a tela do PC em que um circuito foi montado e simulado no Tinkercad

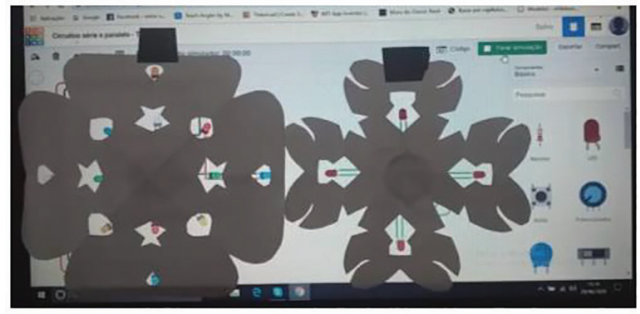

Link para acesso ao vídeo

https://youtu.be/rHD2vWv4Y1U
Circuito abaixo da figura ou desenho atribuído a narrativa
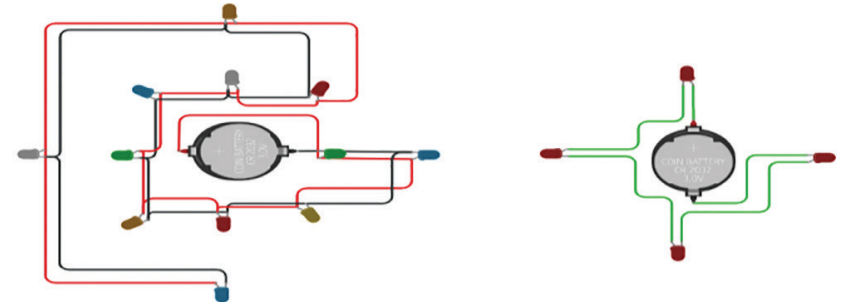

Link para o simulador:

https://www.tinkercad.com/things/beKc7OfjYw7

Autoria: Renata Ribeiro Yamaguti; EMEF Jose Pegoraro; DRE Capela do Socorro: Pagina 51 do Catálogo 33 https://doi.org/10.5281/ZENODO.4618289)

Superposição do desenho com a tela do PC em que um circuito foi montado e simulado no Tinkercad

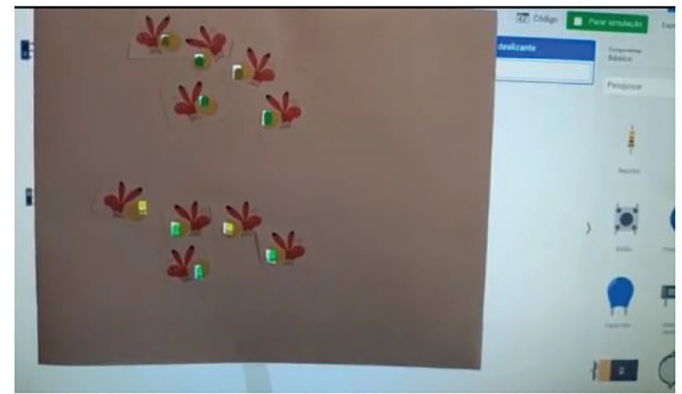

Link para o vídeo: https://youtu.be/UzTyvpA0R00
Circuito abaixo da figura ou desenho atribuído a narrativa
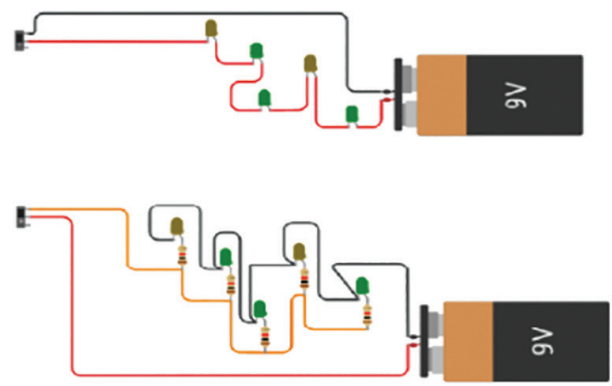

Link tinkercad:

https://www.tinkercad.com/things/kv1cZY2koLC

Circuito Físico projetado a partir do protótipo desenvolvido. O que pode ser realizado em uma aula presencial

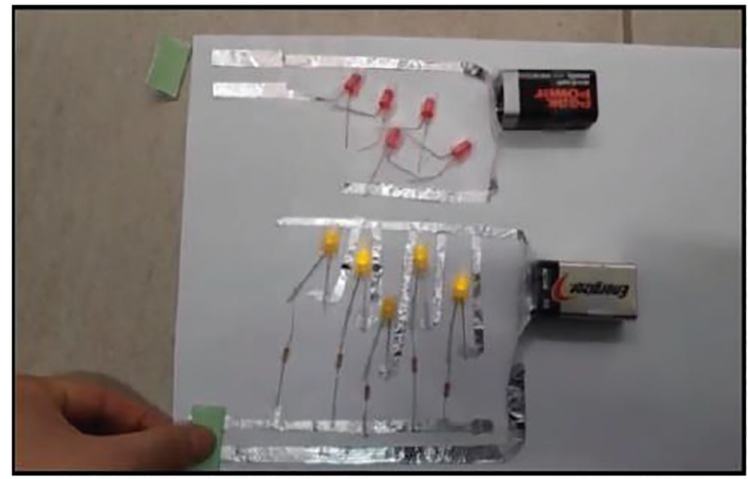

nados ao cotidiano, de relevância indiscutível, a compreensão conceitual ainda apresenta alguns obstáculos, e apontaremos alguns deles.

Vamos considerar, por exemplo, a instalação elétrica residencial e sua correlação com circuitos executados no simulador, citados em alguns artigos. Apesar do planejamento bem estruturado dos diferentes autores, eles apontam a dificuldade dos estudantes em transitar de uma situação micro presente na simulação para algo macro. Na nossa concepção nesta transição envolvemos o desenvolvimento de estruturas cognitivas correlacionadas a diferentes modos de representação da situação problema, tais como a visualização de projetos de plantas baixas, associação de tubulações para a passagem de fiações, a localização e função de interruptores etc. Estas correlações entre os diferentes saberes e múltiplos olhares 
só encontram um terreno fértil se de fato o estudante se sentir motivado. De acordo com a neurociência;

\begin{abstract}
“.. para dar sustentabilidade a esses múltiplos olhares, faz-se necessário pensar numa sociedade que está cada vez mais marcada pela diversidade de informações e culturas, internalizar o diálogo com o cérebro e suas múltiplas funções, interagir com as diversas dimensões, legitimando significados e conhecimentos diversos.... Isto potencializa o despertar de interesses do estudante em aprender de forma intensa" 28].
\end{abstract}

Assim, para que um conhecimento científico seja incorporado a estrutura cognitiva do estudante, o tema deve fazer sentido para a sua vida, em sintonia com seus desejos e de acordo com seu perfil.

Portanto, apesar de instalações elétricas, estarem presentes no cotidiano, pode não ser suficientemente motivador para aqueles que apresentam interesse por áreas artísticas ou humanas, por exemplo. Não se trata de se descaracterizar e atribuir a relevância desta iniciativa, mas de agregar outros métodos e técnicas para aproximar a Física de jovens com outros perfis.

Numa sala de aula da escola básica temos diferentes perfis de estudantes e observa-se um grande interesse dos jovens por áreas correlacionadas a artes, design, jornalismo, psicologia e baixo interesse pelas áreas de ciências exatas - talvez isso se dê em decorrência da distância que se impõe entre Ciência, Arte e Cultura.

O nosso desafio como professores de Física está em despertar o interesse dos estudantes para compreender conceitos abstratos correlacionados à eletricidade, independentemente de suas áreas de interesse. Não existe nenhuma fórmula mágica, mas certamente o caminho para isso, requer um olhar mais amplo no planejamento de estratégias que não priorize o conteúdo em si, mas o trajeto traçado no processo de aprendizagem envolvendo diferentes tipos de habilidades.

Neste contexto, a Arte surge como uma área essencial que contribui na formação de cada um de nós. Ela propicia o desenvolvimento de inúmeras habilidades, desde o apuramento do olhar, do autoconhecimento, e nas diferentes formas de se representar o mundo. A arte nos inspira e contagia, desperta emoções, comunica, proporciona equilíbrio. É alegria, vitalidade e faz parte da vida de todos nós. Desenvolver arte é trazer crescimento explorando o potencial que existe dentro de cada um de nós. Isso contribui significativamente no desenvolvimento da criatividade. Deste modo, a conexão entre Arte e Ciência certamente motivará muito mais crianças e jovens a compreender a ciência.

Sendo que a utilização de conhecimentos científicos na construção de um objeto artístico pode despertar sentimentos que conduzam os jovens a explorar novos caminhos em seu interior por meio da imaginação.
Segundo Bronowski, J. (1983) "Se a ciência é uma forma de imaginação, se toda a experiência é um tipo de jogo, então a ciência não pode ser árida. E no entanto, muitas pessoas julgam que sim; a arte é divertida, mas a ciência é monótona, é outra falácia comum" (apud Pietrocola, 2004, p. 120).

Assim, muitas habilidades importantes na formação do indivíduo podem ser desenvolvidas por meio de produtos que façam conexões entre Arte e Ciência, despertando interesse de diferentes perfis, incluindo aqueles que tem preferência por outras áreas que não apenas aquelas correlacionadas a exatas e engenharias.

"Dentre as disciplinas escolares, creio que as artes sejam as que melhor exemplifiquem o prazer possível de ser obtido com o contato com o conhecimento [...] As artes são capazes de nos sensibilizar de maneira permanente." [29]

Ciência, Arte e Cultura, sempre estiveram conectadas na história do processo de criação humana, no entanto, em sala de aula pouco se tem feito de modo a integrar estas dimensões 30. Segundo [31] os jogos digitais educativos informais podem ser entendidos como obras de arte, potencializando discussões que estão na interface entre Educação Científica e Educação em Direitos Humanos. Para os autores a Arte pode ser um caminho frutífero para reflexões e abordagens didáticas.

Diante destas observações, decidimos optar por construções artísticas como uma forma de representação para a conexão de lâmpadas em circuitos residenciais, tal como o trabalho de pintura chinesa de Jie Qi [7, 8 e outros trabalhos como 32 e 9 que nos serviu de inspiração para o desenvolvimento de painéis interativos. Talvez dentro deste conceito fosse possível atingir um maior número de alunos interessados em descobrir como as coisas funcionam.

Manifestações artísticas e Culturais trazem por si características humanas mais profundas que habitam em todos nós. Integrar arte, ciência e cultura potencializa qualquer processo de aprendizagem.

Assim além de tratar conceitos em eletricidade, aliamos o desenvolvimento de métodos de investigação para teste de hipóteses e compreensão de situações problemas. Porém esta busca de compreensão e investigação emerge da necessidade dos estudantes/professores na construção do seu painel interativo.

\section{Eletrônica criativa no curso de educação continuada para professores de tecnologia da secretaria municipal de educação de São Paulo}

Temos acompanhado uma crescente transformação na organização dos antigos laboratórios de informática das escolas em espaços mais criativos, numa dinâmica de aprendizagem por projetos e na disseminação de uma cultura digital. Um exemplo é a criação tanto em escolas 
particulares quanto públicas dos conhecidos laboratórios Maker. Estas transformações além da aquisição de equipamentos de prototipagem, incluem a formação de professores para orientar estudantes na utilização e criação de tecnologias de forma crítica, reflexiva e ética tanto no convívio social quanto para suas vidas. Como apoio ao processo de formação continuada foram estruturados, pelos autores, um curso de extensão em Computação Física por meio de metodologias ativas e na modalidade remota. Este curso foi aplicado em duas turmas de 50 professores da secretaria municipal de educação de SPBrasil em 2020. A demanda decorreu, dentre outros fatores, do uso crescente de prototipagem com o Arduino como uma das ferramentas que contribui fortemente para o desenvolvimento do pensamento computacional e pela necessidade de um maior domínio desta tecnologia, apontada pelos professores orientadores responsáveis pelos Laboratórios de Educação Digital (LED) das escolas da rede municipal de educação da cidade de São Paulo.

\subsection{Práticas e atividades desenvolvidas pelos participantes do curso}

Aqui apresentamos alguns resultados das práticas realizadas pelos professores durante o processo de aprendizagem sobre eletricidade básica e eletrônica, necessárias em protótipos com o Arduino, não apenas para resolver problemas de natureza técnica, mas no contexto da Eletrônica Criativa. A natureza lúdica e híbrida desta proposta permitiu aos professores ganhar mais segurança no manuseio de sensores e atuadores no desenvolvimento projetos e atividades para aplicação em aulas remotas e presenciais.

A Tabela 2 mostra dois trabalhos de painéis $2 \mathrm{D}$ com circuitos simples (prof. Douglas), e com a construção física do protótipo (profa. Renata). Já a Tabela 3 apresenta uma atividade com o Arduino (profa. Juliana). Estes e outros projetos estão disponíveis no catálogo de projeto e práticas 33 .

Importante lembrar que as atividades desenvolvidas pelos professores são destinadas a crianças do Ensino Fundamental 1 e devem, por esta razão, ter um caráter mais lúdico e com uma compreensão qualitativa do fenômeno em estudo.

O propósito é promover nas crianças a compreensão de conceitos de eletricidade básica para que possam desenvolver seus projetos de robótica com maior propriedade. Tendo a compreensão, mesmo que qualitativa, de sinais elétricos, que estes sinais serão responsáveis por representar alguma grandeza física do ambiente (luz, pressão, temperatura etc.) e por meio deste sinal possamos estabelecer uma correlação entre hardware e software.

Para isso, estes conceitos podem ser desenvolvidos por meio de atividades remotas síncronas e assíncronas. Um aspecto importante no contexto de isolamento social em ocorreu o curso, pois permitiu que os professores de
Tecnologia pudessem desenvolver imediatamente atividades interativas com seus estudantes remotamente.

Neste tipo de atividade os conteúdos de eletrônica são suficientemente compreendidos para que o estudante possa desenvolver o seu protótipo ou seu painel. O painel é criado tomando como base narrativas, o lhe atribui elementos que possibilitam trabalhar a tecnologia de modo transversal e envolvendo várias disciplinas. A eletrônica não é, portanto, um fim em si mesma. É exatamente esta roupagem que faz desta estratégia algo motivador e diferenciado. Esta é uma das razões pela qual denominamos esta estratégia de Eletrônica Criativa.

\subsection{Considerações sobre as atividades desenvol- vidas pelos professores participantes}

Importante notar que as atividades são planejadas de modo que os professores participantes do curso de formação continuada, independentemente do nível técnico, possam contribuir com atividades criativas e interdisciplinares, buscando a integração da área de tecnologia com outras áreas do conhecimento. Este procedimento atribui aos Laboratórios de Educação Digital (LED) uma roupagem transdisciplinar, tal como preconiza a BNCC e o currículo da cidade em Tecnologias para Aprendizagem [34.
"... Diferentes dimensões que caracterizam a computação e as tecnologias digitais são tematizadas, tanto no que diz respeito a conhecimentos e habilidades quanto a atitudes e valores: pensamento computa- cional, ... mundo digital ... e cultura digital ... Portanto, na BNCC dessa etapa, o foco passa a estar no reconhecimento das potencialidades das tecnologias digitais para a realização de uma série de atividades rela- cionadas a todas as áreas do conhecimento, a diversas práticas sociais ao mundo do trabalho." [5]

As atividades propostas pelos professores foram todas desenvolvidas com a intenção de serem aplicadas em suas aulas. O intuito é permitir que as crianças comecem a ter uma compreensão das grandezas associadas aos circuitos elétricos, como corrente elétrica, resistência elétrica, associações entre componentes que aumentam a corrente elétrica total, outras que a reduzem. Para além disso, a percepção de que existe a transformação de uma grandeza associada ao ambiente em sinal elétrico, por meio do uso de sensores. Todo o processamento deste sinal é então efetuado e a programação é realizada tendo como parâmetro esta informação. Dependendo da faixa etária da criança, os cálculos não são necessários e, muitas vezes, nem possíveis de serem realizados. Mas o fundamental é a inserção da criança no contexto da eletrônica e perceber que a automação e as tecnologias que nos rodeia está repleta de eletrônica, de sinais elétricos que podem ser medidos, detectados e 
Tabela 3: Painel 2D projetado com o uso do Arduino. A interação se dá por meio de sensores.

Autoria: Juliana Gomes da Cruz Cabral Costa; EMEF Jd. Silva Teles; DRE São Miguel: pagina 32 do catalogo [33] https://doi.org/10.5281/ZENODO.4618289

Superposição do desenho com a tela do PC em que um Circuito abaixo da figura ou desenho atribuído a circuito foi montado e simulado no Tinkercad narrativa
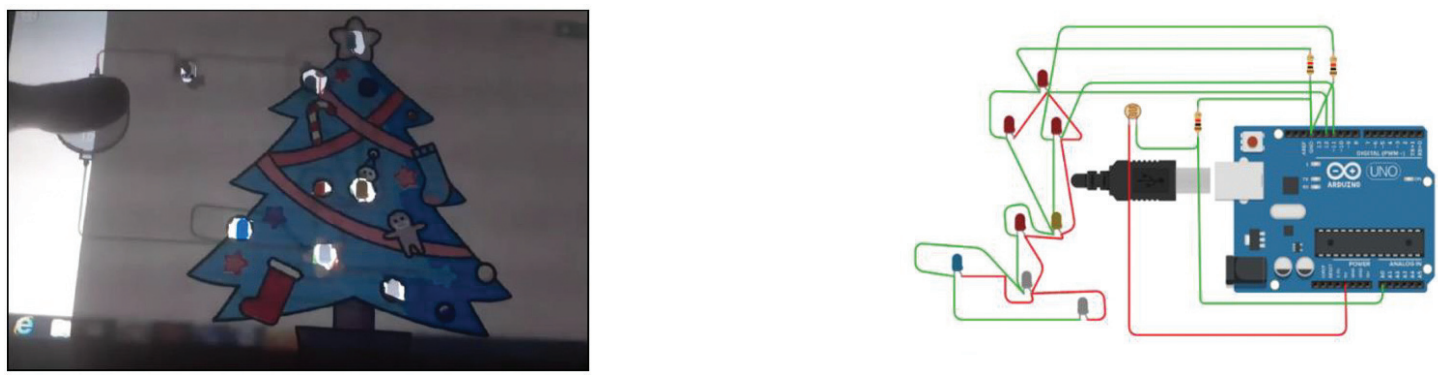

Link para video

https://youtu.be/KtkfRd5Dmq0

Link para tinkercad

https://www.tinkercad.com/things/aBWXdh3PGfZ

processados para devida programação e desenvolvimento de software.

Se trata de um processo que já desloca a criança para o século XXI e permite iniciar sua educação tecnológica desde muito cedo. Para que tudo isso seja possível as atividades devem ser muito bem planejadas e na medida do possível envolver narrativas, preferencialmente trazendo alguma correlação com a realidade vivida pelos estudantes, na comunidade escolar e em seu entorno.

A liberdade de criação e inventividade deve ser fortalecida para que estas crianças possam ser cada vez mais protagonistas da sua própria história e na construção do seu conhecimento.

\section{Análise dos resultados e considerações finais}

Há décadas que pesquisadores na área de ensino de Ciências questionam a estrutura curricular tradicional de disciplinas nas áreas de ciências exatas. Com conteúdo inalterados, desde início do século XX, apesar das grandes descobertas científicas e dos avanços tecnológicos conquistados nos séculos XX e XXI. A ciência que se aprende na escola se encontra há, pelo menos, 1 século de defasagem das investigações cientificas recentes. Os exercícios e problemas utilizados em sala de aula, são praticamente os mesmos há décadas e estão muito distantes da realidade dos nossos jovens. Igualmente para os currículos dos antigos e atuais cursos de formação dos professores. Este raciocínio se estende não apenas no que se refere aos conteúdos, mas também acerca da negação no uso de metodologias de aprendizagem que se amparam na construção coletiva do conhecimento, no desenvolvimento da criatividade e de habilidades socioemocionais.

Diante das grandes transformações possibilitadas pela ciência e a tecnologia surgiram modelos que possibilitam refletir sobre a formação continuada e inicial do pro- fissional em educação. Um dos mais promissores é o modelo TPACK (Technological Pedagogical Content Knowledge). Este modelo institui e busca explicar a base de conhecimento docente para a integração das tecnologias em contextos educacionais, a partir do alinhamento com abordagens pedagógicas e ensino de conteúdo específicos. Para o exercício da profissão "professor" do século XX deve haver uma integração entre os conhecimentos pedagógicos, tecnológicos e de conteúdo específico. Isso traz a atual do docente para uma área de intersecção dos três saberes.

Neste trabalho apresentamos uma metodologia que se adapta ao modelo TPACK, buscando estratégias para a aprendizagem em Eletrônica na modalidade híbrida de ensino. Além da integração TPACK, trazemos para área de atuação do docente o resgate da unificação entre ArteCiência e Cultura que historicamente sempre compôs o processo de construção humana.

Quando consideramos as diferentes possibilidades metodológicas em que se prioriza a experimentação por meio de materiais recicláveis, a inserção de ferramentas digitais e o desenvolvimento da criatividade e inventividade na construção do conhecimento, percebe-se claramente que a Arte assume um papel cada vez mais importante como uma área que fortalece os diferentes modos de representações característico nos processos de ensino e aprendizagem em Ciências.

Vários trabalhos publicados apontam que o uso de simuladores no aprendizado de eletricidade, podem ser até mesmo mais eficazes do que equipamentos reais tendo em vista que traz segurança ao estudante para aprender com seus erros, já que qualquer falha ou desatenção não acarreta a queima de nenhum componente e que não existe nenhuma possibilidade de choque.

O manuseio de equipamentos reais, apesar de trazer muito aprendizado, limita as ações dos estudantes pelo medo de que o seu erro traga prejuízos irreparáveis e isso impede que ele ouse mais e que se auto desafie. 
A contribuição deste trabalho está em trazer a integração entre arte, ciência e cultura na construção deste conhecimento. Assim o aprendizado em eletrônica e/ou eletricidade acontece a partir de outras dimensões que a arte nos oferece, de se relacionar com o mundo e construir conhecimento. Outras representações são envolvidas neste aprendizado na construção de painéis $2 \mathrm{D}$ ou obras híbridas que integram o físico analógico e/ou digital as competências de design e as construções de narrativas educacionais. Esta integração acaba por motivar todos os estudantes independente de seus perfis. O conhecimento em eletricidade ocorre de modo espontâneo e emerge da necessidade de construção de um produto.

As estratégias de ensino utilizadas constituem uma metodologia que chamamos de Eletrônica Criativa e tem sido utilizada tanto na formação inicial quanto na formação continuada. Como resultado da aplicação desta metodologia temos obtido propostas de atividades inclusive já executadas em sala de aulas de Ensino Fundamental e Médio por professores em exercício e que em seus depoimentos apontaram maior motivação dos estudantes e consequente melhora no aprendizado, não apenas do conhecimento específico, mas no desenvolvimento de habilidades para aprender a aprender, aprender a fazer, aprender a conviver e aprender a ser.

No que se refere aos conteúdos abordados neste curso de formação continuada, elencados no item 3 deste artigo, podemos considerar que as estratégias adotadas por meio das estratégias da Eletrônica Criativa, possibilitou aos professores cursistas, que em sua grande maioria não possuíam nenhum conhecimento em eletricidade básica, agregar conteúdo de eletrônica para a compreensão do princípio básico que rege a comunicação entre o meio Físico ao sensoriamento de grandezas físicas, ao processamento do sinal com a correspondente programação do Arduino na sua IDE (ou qualquer outra interface iconográfica) e atuação neste meio das saídas digitais e deste modo, permitiram a devida compreensão do sistema como um todo e das variáveis envolvidas.

\section{Referências}

[1] https://pt.unesco.org/covid19/educationresponse acessado em 16/03/2021.

[2] H.L. Gusso, A.B. Archer, F.B. Luiz, F.T. Sahão, G.G. Luca, M.H.O. Henklain, M.G. Panosso, N. Kienen, O. Beltramello e V.M. Gonçalves, Educ. Soc. 41, e238957 (2020).

[3] https://periodicos.pucpr.br/index.php/dialogoeducaci onal/article/view/7052, acessado em 16/03/2021.

[4] E. Molisani, M. Sacay, M. Cavalcante e J.A. de Freitas, Práticas para aprendizagens híbridas e interdisciplinares envolvendo criação, inventividade e computação física (SME/COPED, São Paulo, 2021).

[5] http://basenacionalcomum.mec.gov.br/abase/\#funda mental/a-area-de-ciencias-da-natureza, acessado em $16 / 03 / 2021$.
[6] P.F.T. Dorneles, I.S. Araujo e E.A. Veit, Rev. Bras. Ensino Física 28, 487 (2006).

[7] https://www.youtube.com/watch?v=C1-pdgGn0SI acessado em 16/03/2021.

[8] http://technolojie.com/pu-gong-ying-tu-dandelion-pa inting/, acessado em 16/03/2021.

[9] A. Zoran, S.O. Valjakka, B. Chan, A. Brosh, R. Gordon, Y. Friedman, J. Marshall, K. Bunnell, T. Jorgensen, F. Arte et al., Leonardo 48, 384 (2015).

[10] N.D. Finkelstein, W.K. Adams, C.J. Keller, P.B. Kohl, K.K. Perkins, N.S. Podolefsky, S. Reid e R. LeMaster, Phys. Rev. Spec. Top. - Phys. Educ. Res. 1, 010103 (2005).

[11] https://dcaclab.com/es/users_experiments, acessado em 17/03/2021.

[12] https://www.tinkercad.com/, acessado em 17/03/2021.

[13] https://phet.colorado.edu/pt_BR/, acessado em 17/03/2021.

[14] http://ufamaulas.blogspot.com/, acessado em 08/07/2021.

[15] http://fisicacomputacaopucsp.blogspot.com/, acessado em 08/07/2021.

[16] https://rexlab.ufsc.br/, acessado em 21/06/2021.

[17] https://www.ises.info/index.php/en/laboratory acessado em 21/06/2021.

[18] https://www.youtube.com/watch?v=OacWNX_yqTE acesso em 18/06/2021.

[19] P. Mishra e M.J. Koehler, Teach. Coll. Rec. 108, 1017 (2006).

[20] https://zenodo.org/record/4615195, acessado em $17 / 03 / 2021$.

[21] https://padlet.com/, acessado em 17/03/2021.

[22] https://www.youtube.com/watch?v=b2Bp6afmHNA acessado em 17/03/2021.

[23] https://edu.google.com/intl/pt-BR/products/jamboar d/, acessado em 19/03/2021.

[24] J.C. dos Santos e A.G. Dickman, Rev. Bras. Ensino Física 41, e20180161 (2019).

[25] F.V. Araújo, F.A.S. Nobre, J.A. Andrade Junior e C.R. da S. Dantas, Informática na Educ. Teor. prática 18, 145 (2016).

[26] A.M. Bastos, Res. Soc. Dev. 9, e205996846 (2020).

[27] R.A. Zara e L.M. Weizenmann, Arq. do Mudi 24, 256 (2020).

[28] M.R.K.F. Rezende, A Neurociência E O EnsinoAprendizagem Em Ciências: Um Diálogo Necessário. Dissertação de Mestrado, Universidade do Estado do Amazonas, Manaus (2008).

[29] M. Pietrocola, Curiosidade e imaginação: os caminhos do conhecimento nas ciências, nas artes e no ensino (Cengage Leaning Edições, São Paulo, 2004).

[30] I. de C. Moreira, Física na Esc. 3, 17 (2002).

[31] R.D.V.L. de Oliveira e J.R.R.T. da Silva, Rev. Eletrônica Ludus Sci. 3, 12 (2020).

[32] https://resenv.media.mit.edu/pubs/papers/Circuit_ske tchbook_Final_small.pdf.

[33] https://zenodo.org/record/4618289\#.YPHnHehKiUk.

[34] http://portal.sme.prefeitura.sp.gov.br/Portals/1/Files/ 50630.pdf 